\title{
LINGUOECOLOGICAL PORTRAIT OF REGIONAL TOPONYMICON: DESCRIPTION ATTRIBUTES ${ }^{1}$
}

\author{
Dmitriy Yu. Ilyin \\ Volgograd State University, Volgograd, Russia
}

\begin{abstract}
Absract. The paper deals with the portraying of the regional toponymicon from the viewpoint of the linguoecological approach, which allows studying the set of local geographical names taking into account the possibility of creating a comfortable language environment for the native speaker. The scale of signs of ecology of a geographical name is determined, the influence of intralinguistic and extralinguistic factors on the formation and development of a regional toponymicon is justified. One of the most important criteria for environmental friendliness is the conformity of the name of a geographical object to the requirements of the language system, in particular, the adaptation of word-building elements to existing top-forms. The ecological character of the regional toponymicon is manifested in the presence of nominations reflecting local features and features of the national character of the inhabitants. The notion 'the degree of uniqueness of the name within the region' is characterized, and the scale of features of the named concept is represented. The possibility of forming corresponding toponymic derivatives, which meets the requirements of the language system, is substantiated. Based on the analysis of the linguistic material, the linguoecological portrait of the regional toponymicon is interpreted from the viewpoint of names that meet the criteria of ecological compatibility, and names that can be designated as linguotoxic.
\end{abstract}

Key words: language system, linguoecology, linguoecological attributes, toponymicon, language portrait, language of the region.

Citation. Ilyin D. Yu. Linguoecological Portrait of Regional Toponymicon: Description Attributes. Vestnik Volgogradskogo gosudarstvennogo universiteta. Seriya 2, Yazykoznanie [Science Journal of Volgograd State University. Linguistics], 2018, vol. 17, no. 3, pp. 99-107. (in Russian). DOI: https://doi.org/10.15688/jvolsu2.2018.3.10

\section{ЛИНГВОЭКОЛОГИЧЕСКИЙ ПОРТРЕТ РЕГИОНАЛЬНОГО ТОПОНИМИКОНА: КРИТЕРИИ ОПИСАНИЯ ${ }^{1}$}

\author{
Дмитрий Юрьевич Ильин \\ Волгоградский государственный университет, г. Волгоград, Россия
}

\begin{abstract}
Аннотация. В статье осуществлено портретирование регионального топонимикона с позиции лингвоэкологического подхода, что позволило изучить совокупность локальных географических названий с учетом возможности создания комфортной языковой среды для носителя языка. Определена шкала признаков экологичности географического названия, обосновывается воздействие на становление и развитие регионального топонимикона внутриязыковых и внеязыковых критериев. Одним из наиболее важных критериев экологичности онима признано соответствие наименования географического объекта требованиям языковой системы, в частности, приспособление словообразовательных элементов к существующим топоформантам. Экологичность регионального топонимикона находит проявление в наличии номинаций, отражающих местные особенности и черты нациоᄋ. нального характера жителей. Охарактеризовано понятие «степень уникальности названия в пределах региона» и Б- представлена шкала признаков названного понятия. Обоснована возможность образования соответствующих Е оттопонимических дериватов, отвечающих требованиям системы языка. На основании анализа языкового матерала лингвоэкологический портрет регионального топонимикона интерпретирован с точки зрения названий, отвечающих признакам экологичности, и наименований, которые возможно обозначить как лингвотоксичные.
\end{abstract}


Ключевые слова: языковая система, лингвоэкология, критерии лингвоэкологичности, топонимикон, языковой портрет, язык региона.

Цитирование. Ильин Д. Ю. Лингвоэкологический портрет регионального топонимикона: критерии описания // Вестник Волгоградского государственного университета. Серия 2, Языкознание. - 2018. - Т. 17, № 3. - C. 99-107. - DOI: https://doi.org/10.15688/jvolsu2.2018.3.10

\section{Лингвоэкология как направление лингвистики}

Обусловленное комплексом интра- и экстралингвистических факторов развитие современного русского языка вызывает, с одной стороны, озабоченность исследователей, рефлексирующих как в связи с понижением общей языковой культуры людей, так и по поводу утраты языком определенных его элементов, а с другой - удовлетворенность, основанную на понимании языка как динамичной системы, то есть системы, способной эволюционировать. Очевидна неоднозначность восприятия современной языковой ситуации. Например, весьма категоричны в своих оценках лингвисты, по мнению которых «состояние русской речи... свидетельствует о нравственном неблагополучии общества, о снижении интеллектуальной планки, о неготовности многих вчерашних школьников к получению полноценного высшего образования. Заметного сдвига в сторону повышения уровня речевой культуры общества в целом не происходит, противоречивы и предлагаемые пути выхода из культурно-речевого кризиса» [Козырев, Черняк, 2012, с. 27], «в XX в. русский язык отстал в своем развитии от многих современных языков» [Брусенская, Куликова, 2016, c. 7]. Мотивированной с лингвистической точки зрения и лишенной необоснованного критицизма представляется позиция, согласно которой современные носители языка являются «свидетелями либерализации языка, речевых норм в печати, возникновения принципиально иных стилистических стандартов в новых массмедиа, участниками информационной революции» [Рацибурская, Самыличева, Шумилова, 2015, с. 6]. По мнению одного из ведущих специалистов в области культуры речи О.Б. Сиротининой, современное состояние русской речи характеризуют такие черты, как «огрубление, стилистическое снижение в целом, усиление штампованности, ослабление самоконтроля за речью, сдвиги в ориентирах языковых ценностей (эталонов речи), в соотношении типов речевой культуры» [Сиротинина, 2013, с. 31].

Пониманию современной языковой ситуации способствует новое направление лингвистики, обозначенное разными по этимологическому и содержательному наполнению терминами - «лингвоэкология», «экология языка», «эколингвистика» (см., например: [Ильинова, 2010; Кравченко, 2014; Полухин, 2009; Яковлев, 2016 и др.]). Статус этого направления определяется учеными неоднозначно, что отражается прежде всего в дефиниции термина. Так, Н.Н. Кислицына считает, что эколингвистика - это «раздел языкознания, сформировавшийся на стыке социального (соотношение социальных и языковых структур в процессе развития мышления на разных ступенях этногенеза), психологического (проблемы речевого воздействия) и философского (проявление в языке предельно общих свойств и закономерностей развития общества и познания) направлений в лингвистике» [Кислицына]. Диссонирует с такой трактовкой позиция В.И. Карасика, согласно которой лингвоэкология - это новое измерение социолингвистики, поскольку основные задачи наук (социальная дифференциация языка вследствие социального расслоения общества, социальные условия развития и функционирования языка) совпадают (см.: [Карасик, 2013]). Рассуждения о терминологии этого лингвистического направления, обусловленные накоплением эмпирического и практического знаний, приводят Н.А. Курашкину к выводу о том, что «лингвоэкология» - «“"зонтичный” термин для широкого спектра подходов, преследующих разнообразные цели» [Курашкина, 2015, с. 152].

Междисциплинарный характер научного направления, основной задачей которого является «сохранение языковой идентичности этноса и на этой основе нравственного здоровья общества и национальной безопасности государства» [Бернацкая, 2014, с. 28], позволяет считать наиболее удачным термин «лингво- 
экология», который интерпретирован А.П. Сковородниковым следующим образом: «междисциплинарное направление исследований, в основе которого лежат языкознание и экология (биоэкология и социальная экология) и предметом которого является состояние языка и среды его обитания; факторы, влияющие (негативно или позитивно) на состояние и развитие языка, языкового сознания социума и его речевой культуры; пути и способы защиты языка от негативных влияний, в том числе от не мотивированных социальными и культурными потребностями внешних и внутренних заимствований, вульгаризации речи, лексической и фразеологической эрозии (обеднения) и т. д., а также нахождение способов обогащения языка и условий его оптимального развития» [Экология русского языка, 2017, с. 113].

Принимая во внимание тот факт, что одна из основных задач лингвоэкологии - исследование состояния языка как сложной синтаксической системы, состояния, обусловленного качеством среды «обитания» и функционирования, а также языковым сознанием его носителей [Сковородников, 2016, с. 21-22], следует подчеркнуть: в рамках лингвоэкологии язык и текст как речевой продукт рассматриваются в аспекте их воздействия на отдельную языковую личность и общество в целом, анализируется роль языка в описании экологических ситуаций и выявляются способы устранения негативных последствий, изучается отражение вопросов экологии в языкознании, при этом в описании проблем окружающей внеязыковой действительности применяется лингвистическая терминология и методология. Следовательно, можно говорить о трансформации языкознания как науки преимущественно теоретической, описательной в науку деятельностную, призванную предлагать конкретные решения проблем сокращения языкового разнообразия, не оправданного с точки зрения системы.

\section{Портретирование как метод выявления \\ экологичности языковых ресурсов}

В настоящее время в пространство лингвоэкологических исследований включаются все новые и новые объекты, в частности, ре- гиональный топонимикон - «совокупность лексем, которые используются для наименования географических объектов, расположенных на данной территории, и, отражая особенности конкретной местности, обладают своеобразным семантико-смысловым потенциалом, реализуемым в процессе функционирования» [Ильин, 2012, с. 64]. Кроме того, расширяется методологическая база лингвоэкологии: научные методы, эффективность которых доказана исследованиями в других направлениях лингвистики, адаптируются для решения задач лингвоэкологии. Так, в изучении языка и речи портрет и портретирование как метод лингвистического исследования последовательно реализуются в рамках лингвистической персонологии, сосредоточенной на определении особенностей, характерных для языковой или речевой личности (см.: [Винокур, 1989; Иванцова, 2010; Канчер, 2000; Шмелева, 2010]). По принципу смежности портретирование используется сегодня и при исследовании артефактов, в частности, при выявлении своеобразия того или иного города, региона, а также жанра, газеты или журнала (см.: [Кайда, 2008; Шипицина, Свистельникова, 2010]). Языковые и речевые портреты отражают свойственную для портретируемого субъекта или артефакта совокупность его характеристик как сложной целостности, в рамках которой прописываются доминантные и периферийные признаки изучаемого объекта. Создаются портреты лексикографических источников, характеризуемых с лингвоэкологических позиций (см.: [Жданова, 2013]).

Применительно к анализу регионального топонимикона в лингвоэкологическом аспекте портретирование позволяет изучать этот феномен с учетом возможности создания для носителя языка «комфортной» языковой среды.

В связи с этим отметим: обращение к научной литературе показывает, что четкие критерии определения экологичности / неэкологичности языкового (речевого) факта - «отличительные признаки, на основе которых производится оценка, констатация экологичности или неэкологичности слова в широком понимании (не только как слова, но и высказывания, и текста в целом)» [Экология русского языка, 2017, с. 102] - пока не выработаны, что объясняется совокупностью причин. Харак- 
теризуя речевые и текстовые явления, рассматриваемые как факты среды жизнедеятельности людей, С.В. Ионова называет такие усложняющие факторы выделения критериев экологичности, как разные виды и эффекты воздействия среды на человека, вторичность допускающей определенную погрешность информационной среды по сравнению с естественной материальной средой обитания человека, структурная разнородность объекта информационного влияния, опосредованность воздействия информационной среды (см.: [Ионова, 2013]). Г.А. Копнина к наиболее важным относит такие компоненты экологического состояния языка, как «сферы его функционирования; внутренняя стратификация языка; наличие кодификации; вербализация в языке морально-этических концептов; негативно влияющие на развитие языка факторы и т. д.» [Копнина, 2014, с. 82].

С учетом того факта, что определение шкалы признаков экологичности, на основании которых возможен анализ конкретного языкового материала, до сих пор является важной лингвистической задачей, все же можно утверждать, что на становление и функционирование регионального топонимикона оказывают воздействие внутриязыковые и внеязыковые (природно-географические особенности, специфика социально-экономического и историко-культурного развития региона) факторы экологичности местных географических названий.

\section{Признаки экологичности топонимикона Волгоградской области}

Волгоградская область - крупный субъект Российской Федерации, на территории которого постоянно проживают более двух с половиной миллионов человек. В соответствии с официально утвержденным в 2016 г. «Реестром административно-территориальных единиц и населенных пунктов Волгоградской области» в регионе насчитывается 475 муниципальных образований, из них 6 городских округов, 32 муниципальных района, 29 городских и 408 сельских поселений. Столь обширный массив географических имен собственных, появившихся в разное время и под влиянием языков и культур разных этносов, населявших и населяющих территорию Вол- гоградской области (о формировании ее топонимикона см.: [Воробьев, 2004; Долгачев, 1989; Кудряшова, Северьянова, 1991; Супрун, 1994]), включает различные с точки зрения экологичности единицы и отражает процессы «лингвистической гармонизации».

1. В топонимиконе обнаруживается соответствие наименований географического объекта требованиям языковой системы. Значимой является морфолого-деривационная адаптация проприативов - приспособление словообразовательных элементов русского языка к существующим топоформантам, способствующее сближению их функциональных возможностей. Наиболее показательны в этом плане ойконимы западноевропейского происхождения, привнесенные в топонимикон региона в XVIII-XIX вв. иностранными переселенцами, преимущественно немцами-колонистами. Названия типа Александрталь, Лизандердорф, Мариенфельд, Обердорф, Розенберг и подобные, имевшие иную морфемную структуру в языке-источнике, в русском языке подверглись переосмыслению, поскольку языковая компетенция носителей русского языка не позволяла произвести морфемный анализ, соответствующий структуре немецкого языка. Помимо этого, названия подобных населенных пунктов с повторяющимися структурными элементами (-тал'-, -дор $\phi$-, -фельд-, -берг и т. д.) не воспринимались в топонимическом ряду чужеродной языковой среды и не давали возможности определить наличие подобных повторений для местных жителей, так как эти поселения не обладали свойством территориальной концентрации. Система русского языка адаптировала топонимическую единицу к своим морфемно-деривационным параметрам.

2. Экологичность регионального топонимикона проявляется в наличии в нем номинаций, отражающих местные особенности и черты национального характера жителей. Так, исторически закономерны названия село Новая Полтавка, хутор Киевка, деревня Харьковка: они свидетельствуют о том, что первые жители в эти населенные пункты пришли с Украины (см.: [Кудряшова, 1997, с. 87]) корневые морфемы этих онимов по своей структуре соответствуют названиям украинских городов Полтава, Киев, Харьков, а то- 
поформант -к- со значением «помещение, сооружение, учреждение, место, пространство, географический объект» ${ }^{2}$ дает возможность отнести эти названия к ойконимам.

Этнокультурная определенность имени собственного может быть обусловлена диалектными обозначениями из сферы апеллятивной лексики. В частности, лимноним озеро Кужное получил номинацию от распространенного в этой местности названия болотного растения куга; потамоним река Сакарка - от диалектного обозначения одной из разновидности тополя - сокаря [Кудряшова, 1997, c. 39]. Традиции и обычаи казаков получают отражение в названии возвышенности курган Пьяный, поскольку именно у его подножия казаки-новобранцы, уходившие на службу в царскую армию, пили последнюю чарку [Чемякин, 2005, с. 113].

3. По-разному характеризуются единицы регионального топонимикона по «степени уникальности названия в пределах региона». Это понятие отражает «противоречие между предполагаемой уникальностью топонимического пространства региона и стандартностью топонима, обусловленной общей ментальной основой» [Ильин, Сидорова, 2016, с. 42]. На основании анализа наименований населенных пунктов Волгоградской области Е.Г. Сидорова выделила четыре степени уникальности названия: 1) максимальной степенью характеризуются собственно уникальные ойконимы (Катричев, Лопуховка); 2) высокой степенью обладают однокоренные морфемно близкие наименования (Захаров, Захаровка, Захаровский); 3) средней степенью характеризуются сложные или составные ойконимы с совпадающим опорным компонентом, который может функционировать и в качестве отдельного наименования (Новоцарищынский, Среднецарииынский; Верхняя Липовка, Нижняя Липовка, Липовка); 4) низкой степенью обладают тождественные ойконимы (в Волгоградской области существуют несколько населенных пунктов Александровка, Громки, Захоперский, Каменка, Котовский, Макаровский, Рассвет и др.) [Сидорова, 2015].

Целесообразность введения понятия «степени уникальности названия» детерминируется тем обстоятельством, что основная функция проприативов - выделение из класса однородных объектов единичного посредством закрепления за ним наименования, способного выполнить идентифицирующую функцию. К названиям, которые в полной мере отвечают заявленному требованию, можно отнести большое количество онимов Волгоградской области, среди которых хутор Барбаши, озеро Барманцак, гора Ергени и др. В то же время языковая, историческая, культурная общность этноса, представители которого проживают на той или иной территории, зачастую приводит к стандартности топонима. Следствием общности признаков, зафиксированных в именах собственных, можно считать появление совпадающих наименований поселений, что, не способствуя уникальности топонимического пространства региона, нарушает требование экологичности. В частности, на территории Волгоградской области зафиксированы по два хутора Озерки (в Иловлинском и Киквидзенском районах), три поселка Рассвет (в Иловлинском, Котельниковском и Ленинском районах), шесть хуторов Ольховский (в Кумылженском, Нехаевском и по два населенных пункта с этим же названием в Алексеевском и Урюпинском районах). Поскольку топонимы по своей сути предназначены для выделения единичных объектов в ряду подобных, трудно не согласиться с А.А. Бернацкой в том, что «название неразрывно связано с обозначаемым и должно ему соответствовать» [Бернацкая, 2014, с. 17]. При этом вряд ли, например, топоним Гусын$\kappa a$ способен выполнить идентифицирующую функцию даже в топонимическом пространстве Волгоградской области, если принять во внимание то, что в регионе зафиксированы проприативы балка Гусынка, пруд Гусынка, река Гусынка.

Одним из способов избежать полного совпадения в названии поселения, видимо, можно считать появление «номерных названий» типа село Жутово 1-е, село Жутово 2-е в Октябрьском районе; хутор Княженский 1-й, хутор Княженский 2-й в Михайловском районе; хутор Ярской 1-й и хутор Ярской 2-й в

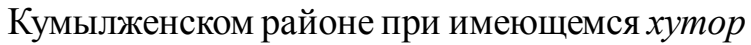
Ярской в Чернышковском районе области. Такие «номерные названия» не способствуют экологичности топонимического пространства в силу ряда причин: затруднительности в про- 
изношении, непоследовательной фиксации на письме (ср.: хутор Первая Березовка, хутор Ильменский-2, село Жутово 2-е), неточного отражения заявленной нумерации (так, в Ленинском районе Волгоградской области есть поселок Лесхоз 5-ц̆, хотя ни в Ленинском районе, ни в другом районе области нет населенных пунктов Лесхоз), путаницы при нахождении населенного пункта. Наличие подобных наименований не отвечает критерию экологичности топонима, поскольку входит в противоречие с принципом витальности, под которым понимается «способность языка к дальнейшему развитию, изменению или сохранению структурных и, главным образом, функциональных качеств. <..> Витальность языка может определяться не функциональной разновидностью, а реальными коммуникативными потребностями языкового сообщества, для которого данный язык является необходимым» [Словарь социолингвистических терминов, 2006, с. 37].

В целях устранения дублирования в название населенного пункта, как правило небольшого по занимаемой территории, включается дополнительный дифференциальный признак, характеризующий ойконим либо с точки зрения особенностей географического расположения занимаемой площади, либо с точки зрения времени его возникновения. Сp. комонимы: хутор Верхнесолоновский - хутор Нижнесолоновский, хутор Большой Дубовский - хутор Мальй Дубовский, станииа Новогригорьевская - станииа Старогригорьевская, село Новый Кондаль село Старый Кондаль.

Наиболее востребованным способом дифференциации онимов следует считать использование однокоренных названий, различающихся наличием тех или иных аффиксальных морфем, ср.: хутор Камышии - город Камыпиин хутор Камышинский - хутор Камылшовка.

4. С позиций лингвоэкологического подхода представляется достаточно существенной возможность отвечающего требованиям системы языка образования оттопонимических дериватов, которые обозначают жителей того или иного населенного пункта. В частности, вызывает сложности образование катойконимов, обозначающих названия жителей населенного пункта, от наименований село
Каршевитое, поселок Красный Пахарь, село Попки и др., что не позволяет положительно оценить их с точки зрения лингвоэкологии (подробнее см.: [Ильин, Сидорова, 2015]).

«Лингвотоксичными» ввиду неудобства их произношения (возможно, и орфографического оформления) следует признать многокомпонентные наименования типа поселок Областной Сельскохозяйственной Опьтной Станции, поселок Фермы № 3 Племзавода «Парижская Коммуна», а также противоречащие современному настроению общества географические названия хутор Красный Мелиоратор, поселок Красный Буксир, поселок Коммунар, поселок Маяк Октября, село Политотдельское, поселок Вторая Пятилетка, поселок Ленинец.

\section{Выводы}

Проведенное исследование дало возможность выявить критерии лингвоэкологичности топонима, к которым, во-первых, относится необходимость соответствия наименования географического объекта требованиям языковой системы, во-вторых, отражение в названии географического объекта местных особенностей и черт национального характера жителей, в-третьих, соблюдениетребования уникальности наименования в пределах региона, в-четвертых, образование оттопонимических дериватов.

Экологичными следует признать топонимические единицы, морфолого-словообразовательная структура которых адаптирована к системе русского языка, такие единицы отражают местные особенности и черты национального характера жителей, имеют максимальную степенью уникальности названия в пределах региона, способны к образованию оттопонимических дериватов в соответствии с требованиями языковой системы. Как «лингвотоксичные» возможно охарактеризовать онимы, словообразовательные элементы которых не соответствуют русским топоформантам, этнокультурная определенность таких названий не коррелирует с русской (славянской) лингвокультурой, они характеризуются средней или низкой степенью уникальности в пределах региона, не способны к образованию оттопонимических дериватов или образуют их с отклонениями от требований языковой системы. 
Таким образом, лингвоэкологический портрет регионального топонимикона формируется официально закрепленными местными географическими названиями, большая часть которых удовлетворяет требованиям языковой системы и не противоречит коммуникативным потребностям носителей языка, проживающих на территории данного региона, а меньшая часть - не соответствует требованиям системы языка и коммуникативным потребностям жителей.

\section{ПРИМЕЧАНИЯ}

${ }^{1}$ Исследование выполнено при финансовой поддержке Российского фонда фундаментальных исследований, проект № 18-12-00641 «Лингвоэкологический портрет регионального топонимикона: проблемы, противоречия и поиски решений».

${ }^{2}$ См.: Лопатин В. В., Улуханов И. Г. Словарь словообразовательных аффиксов современного русского языка. М. : Издательский центр «Азбуковник», 2016. С. 454.

\section{СПИСОК ЛИТЕРАТУРЫ}

Бернацкая А. А., 2014. Лингвоэкология и «критика языка» // Экология языка и коммуникативная практика. № 2. С. 15-31.

Брусенская Л. А., Куликова Э. Г., 2016. Экологическая лингвистика. М. : ФЛИНТА : Наука. 184 с.

Винокур Т. Г., 1989. Речевой портрет современного человека // Человек в системе наук. М. : Наука. С. 361-370.

Воробьев А. В., 2004. От Эльтона до Урюпинска. Волгоград : Станица-2. 174 c.

Долгачев И. Г., 1989. Язык земли родного края: [географические названия Волгоградской области]. 2-е изд., перераб. и доп. Волгоград : Ниж.-Волж. кн. изд. 144 с.

Жданова О. П., 2013. Лингвоэкологический портрет толкового словаря начала XXI века // Экология языка и коммуникативная практика. № 1. C. $65-83$.

Иванцова Т. В., 2010. Лингвоперсонология: Основы теории языковой личности. Томск : Изд-во Томск. ун-та. $160 \mathrm{c}$.

Ильин Д. Ю., 2012. Топонимическая лексика в текстах региональных газет конца XIX - начала XXI века: динамические процессы. Волгоград : Изд-во ВолГУ. 408 с.

Ильин Д. Ю., Сидорова Е. Г., 2015. Деривационные возможности топонимической системы: образо- вание и функционирование катойконимов // Beстник Волгоградского государственного университета. Серия 2, Языкознание. № 3 (27). С. 7-14. DOI: http://dx.doi.org/10.15688/jvolsu2.2015.3.1

Ильин Д. Ю., Сидорова Е. Г., 2016. Проблемы параметрического описания топонима в региональном словаре-справочнике // Русская лексикография XXI века: проблемы и способы их решения : Материалы докладов и сообщений международной научной конференции / отв. ред. М. Л. Каленчук. М. : Ин-т рус. яз. им В.В. Виноградова РАН. С. 42-45.

Ильинова Е. Ю., 2010. Эколингвистический модус событийности в пространстве массмедийного дискурса // Вестник Волгоградского государственного университета. Серия 2, Языкознание. № 2 (12). С. 168-176.

Ионова С. В., 2013. Признаки экологичности и проблема их выделения в лингвоэкологии // Эмотивная лингвоэкология в современном коммуникативном пространстве : колл. монография. Волгоград : Перемена. С. 89-97.

Кайда Л. Г., 2008. Эссе: стилистический портрет. М. : Флинта. $184 \mathrm{c}$.

Канчер М. А., 2000. О трех аспектах описания языковой личности // Культурно-речевая ситуация в современной России. Екатеринбург : Изд-во Урал. ун-та. С. 311-318.

Карасик В. И., 2013. Ценностные параметры лингвоэкологического общения // Эмотивная лнгвоэкология в современном коммуникативном пространстве : колл. монография. Волгоград : Перемена. С. 191-201.

Кислицына Н. Н. Эколингвистика - новое направление в языкознании. URL: http://www.crimea.edu/ tnu/magazine/culture/culture37/part1/zip/ kislitsina.zip (дата обращения: 16.08.2018).

Козырев В. А., Черняк В. Д., 2012. Современная языковая ситуация и речевая культура. М. : ФЛИНTA : Наука. 184 с.

Копнина Г. А., 2014. Экология языка и экология речи как разделы эколингвистики // Экология языка и коммуникативная практика. № 2. C. $78-89$.

Кравченко А. В., 2014. Два взгляда на экологию языка и экологическую лингвистику // Экология языка и коммуникативная практика. № 2. C. 90-99.

Кудряшова Р. И., 1997. Слово народное. Говоры Волгоградской области в прошлом и настоящем. Волгоград: Перемена. $124 \mathrm{c}$.

Кудряшова Р. И., Северьянова А. А., 1991. Своеобразие топонимии территории позднего заселения // Ономастика Поволжья : материалы VI конф. по ономастике Поволжья. Волгоград : Перемена. С. 29-36. 
Курашкина Н. А., 2015. Эколингвистика или лингвоэкология? Терминологическая дилемма междисциплинарной научной области // Экология языка и коммуникативная практика. № 2. С. 143-156.

Полухин А. А., 2009. Современное языкознание и эколингвистическоемышление// Опыты-2008: Сборник научных работ преподавателей и студентов факультета филологии / Сост. Н. М. Димитрова. СПб.: РИОГПА. С. 65-73.

Рацибурская Л. В., Самыличева Н. А., Шумилова А. В., 2015. Специфика современного медийного словотворчества. М. : ФЛИНТА : Наука. 136 с.

Сидорова Е. Г., 2015. Лингвоэкологические проблемы топонимического пространства региона // Экология языка и коммуникативная практика. № 2. С. 157-166.

Сиротинина О. Б., 2013. Русский язык: система, узус и создаваемые ими риски. Саратов : Изд-во Сарат. ун-та. 116 c.

Сковородников А. П., 2016. Экология русского языка. Красноярск : Сиб. федер. ун-т. 388 с.

Словарь социолингвистических терминов, 2006. Словарь социолингвистических терминов / отв. ред. В. Ю. Михальченко. М. : Ин-т языкознания РАН. 312 c.

Супрун В. И., 1994. О проекте словаря гидронимов Волгоградской области // Вопросы краеведения : материалы V краевед. чтений. Волгоград: Перемена. Вып. 3. С. 191-194.

Чемякин Е. А., 2005. Казачьи фамилии и.... (этимология, гидротопонимика, краеведение). Волгоград : Принт. 159 с.

Шипицына Г. М., Свистельникова С. А., 2010. К речевому портрету оппозиционной газеты: заголовки заметок // Политическая лингвистика. № 4 (34). С. 70-74.

Шмелева Т. В, 2010. Портретирование как стратегия лингвистического исследования // Записки филиала РГГУ в г. Великий Новгород. Вып. 8. Историко-культурный и экономический потенциал России: наследие и современность. Великий Новгород : Виконт. С. 193-197.

Экология русского языка, 2017. Экология русского языка. Словарь лингвоэкологических терминов / авт.сост. д-р филол. наук, проф. А. П. Сковородников. М. : ФЛИНТА : Наука. 384 с.

Яковлев А. А., 2016. Три вопроса о языковой картине мира - три вопроса об экологии терминосистемы языкознания // Экология языка и коммуникативная практика. № 2. С. 39-50.

\section{REFERENCES}

Bernatskaya A.A., 2014. Linguistic ecology and 'language criticism'. Ekologiya yazyka $i$ kommunikativnaya praktika [Ecology of Language and Communicative Practice], no. 2, pp. 15-31.

Brusenskaya L.A., Kulikova E.G., 2016. Ecological linguistics. Moscow, Flinta; Nauka Publ. 184 p.

Vinokur T.G., 1989. Speech portrait of a modern person. Chelovek v sisteme nauk. Moscow, Nauka Publ, pp. 361-370.

Vorobyev A.V., 2004. From Elton to Uryupinsk. Volgograd, Stanitsa-2 Publ. $174 \mathrm{p}$.

Dolgachev I.G., 1989. Language of the Native Land: geographical names of the Volgograd region. Volgograd, Nizhne-Volzhskoe izd-vo. 144 p.

Zhdanova O.P., 2013. Linguo-ecological portrait of the explanatory dictionary of the Russian language at the turn of the $21^{\text {st }}$ century. Ekologiya yazyka $i$ kommunikativnaya praktika [Ecology of Language and Communicative Practice], no. 1, pp. 65-83.

Ivantsova T.V., 2010. Linguistic personology: Fundamentals of the theory of language personality. Tomsk, Izd-vo TGU. $160 \mathrm{p}$.

Ilyin D.Yu., 2012. Toponymic lexicon in the texts of regional newspapers of the late $19^{\text {th }}$ - early $21^{\text {st }}$ century: dynamic processes. Volgograd, Izd-vo VolGU. 408 p.

Ilyin D.Yu., Sidorova E.G., 2015. Derivational potential of toponymical system: formation and functioning of Katoikonyms. Vestnik Volgogradskogo gosudarstvennogo universiteta. Seriya 2, Yazykoznanie [Science Journal of Volgograd State University. Linguistics], no. 3 (27), pp. 7-14. DOI: http://dx.doi.org/10.15688/jvolsu2.2015.3.1.

Ilyin D.Yu., Sidorova E.G., 2016. Problems of the parametric description of the toponym in the regional dictionary-reference book. Kalenchuk M.L., ed. Russkaya leksikografiya XXI veka: problemy $i$ sposoby ikh resheniya : Materialy dokladov $i$ soobshcheniy mezhdunarodnoy nauchnoy konferentsii. Moscow, In-t rus. yaz. im V.V. Vinogradova RAN, pp. 42-45.

Ilyinova E.Yu., 2010. Ecolinguistic view on eventus modus in mass media discourse. Vestnik Volgogradskogo gosudarstvennogo universiteta. Seriya 2, Yazykoznanie [Science Journal of Volgograd State University. Linguistics], no. 2 (12), pp. 168-176.

Ionova S.V., 2013. Signs of ecological compatibility and the problem of their isolation in linguoecology. Emotivnaya lingvoekologiya $v$ sovremennom kommunikativnom prostranstve: koll. monografiya. Volgograd, Peremena Publ., pp. 89-97.

Kaida L.G., 2008. Essays: stylistic portrait. Moscow, Flinta Publ. $184 \mathrm{p}$.

Kancher M.A, 2010. About three aspects of language personality description. Kulturno-rechevaya 
situatsiya v sovremennoy Rossii. Ekaterinburg, Izd-vo Ural. un-ta, pp. 311-318.

Karasik V.I., 2013. Values of linguoecological communication. Emotivnaya lngvoekologiya $v$ sovremennom kommunikativnom prostranstve: koll. monografiya. Volgograd, Peremena Publ., pp. 191-201.

Kislitsyna N.N. Ecolinguistics is a new direction in linguistics. URL: http://www.crimea.edu/tnu/ magazine/culture/culture37/part1/zip/kislitsina. zip (accessed 16 August 2018).

Kozyrev V.A, Chernyak V.D., 2012. Modern language situation and speech culture. Moscow, Flinta; Nauka Publ. 184 p.

Kopnina G.A., 2014. Ecology of language and ecology of speech as ecolinguistic's sections. Ekologiya yazyka i kommunikativnaya praktika [Ecology of Language and Communicative Practice], no. 2, pp. 78-89.

Kravchenko A.V., 2014. Two views on the ecology of language and ecolinguistics. Ekologiya yazyka i kommunikativnaya praktika [Ecology of Language and Communicative Practice], no. 2, pp. 90-99.

Kudryashova R.I., 1997. The folk word. Dialects of the Volgograd region in the past and present. Volgograd, Peremena Publ., 124 p.

Kudryashova R.I., Severyanova A.A., 1991. The peculiarities of the toponymy of the territory of late settlement. Onomastika Povolzhya: materialy VI konf. po onomastike Povolzhya. Volgograd, Peremena Publ., pp. 29-36.

Kurashkina N.A., 2015. Ecolinguistics or linguoecology? Terminological dilemma of interdisciplinary scientific area. Ekologiya yazyka i kommunikativnaya praktika [Ecology of Language and Communicative Practice], no. 2, pp. 143-156.

Polukhin A.A., 2009. Modern linguistics and ecolinguistic thinking. Dimitrova N.M., ed. Opyty2008: Sbornik nauchnykh rabot prepodavateley $i$ studentov fakulteta filologii. Saint Petersburg, RIO GPA Publ., pp. 65-73.
Ratsiburskaya L.V., Samylicheva N.A., Shumilova A.V., 2015. Specificity of modern media word-making. Moscow, Flinta Publ. 136 p.

Sidorova E.G., 2015. Lingua-ecological problems of toponimic space of a region. Ekologiya yazyka $i$ kommunikativnaya praktika [Ecology of Language and Communicative Practice], no. 2, pp. 157-166.

Sirotinina O.B., 2013. The Russian language: the system, the usage and the risks they create. Saratov, Izd-vo SGU. $116 \mathrm{p}$.

Skovorodnikov A.P., 2016. Ecology of the Russian language. Krasnoyarsk, Sib. feder. un-t. 388 p.

Mikhaylchenko V.Yu., 2006. Dictionary of sociolinguistic terms. Moscow, Institute of Linguistics. $312 \mathrm{p}$.

Suprun V.I., 1994. About the project of the dictionary of hydronyms of the Volgograd region. Voprosy kraevedeniya: materialy $V$ kraeved. chteniy. Volgograd, Peremena Publ., iss. 3, pp. 191-194.

Chemyakin E.A., 2005. Cossack surnames and .... (etymology, hydrotoponymy, local history). Volgograd, Print Publ. $159 \mathrm{p}$.

Shipitsyna G.M., Svistelnikova S.A., 2010. In reference to the speech portrait of the opposition newspaper: article headlines. Politicheskaya lingvistika [Political Linguistics], no. 4(34), pp. 70-74.

Shmeleva T.V., 2010. Portraiting as a strategy of linguistic research. Zapiski filiala $R G G U \vee g$. Velikiy Novgorod. Vyp. 8. Istoriko-kulturnyy $i$ ekonomicheskiy potentsial Rossii: nasledie $i$ sovremennost. Velikiy Novgorod, Vikont Publ., pp. 193-197.

Skovorodnikov A.P., 2017. Ecology of the Russian language. Dictionary of linguoecological terms. Moscow, Flinta Publ. 384 p.

Yakovlev A.A., 2016. Three questions about linguistic worldview as three questions about ecology of the linguistics terminology. Ekologiya yazyka $i$ kommunikativnaya praktika [Ecology of Language and Communicative Practice], no. 2, pp. 39-50.

\section{Information about the Author}

Dmitriy Yu. Ilyin, Doctor of Sciences (Philology), Associate Professor, Head of Department of Russian Philology and Journalism, Volgograd State University, Prosp. Universitetsky, 100, 400062 Volgograd, Russia, dilyin@volsu.ru, https://orcid.org/0000-0001-6387-757X

\section{Информация об авторе}

Дмитрий Юрьевич Ильин, доктор филологических наук, доцент, заведующий кафедрой русской филологии и журналистики, Волгоградский государственный университет, просп. Университетский, 100, 400062 г. Волгоград, Россия, dilyin@volsu.ru, https://orcid.org/0000-0001-6387-757X 